\title{
WLB in Zahlen 2020
}

\begin{tabular}{|c|c|}
\hline \multicolumn{2}{|l|}{ Gesamtbestand (Stand: 26.2.2021) } \\
\hline Medienbestand insgesamt & 6.237 .900 \\
\hline \multicolumn{2}{|l|}{ davon: } \\
\hline Buchmaterialien & 4.167 .275 \\
\hline Autographen & 180.682 \\
\hline Handschriften & 15.587 \\
\hline Inkunabeln & 7.093 \\
\hline Noten & 79.520 \\
\hline Karten & 157.906 \\
\hline Mikroformen & 489.607 \\
\hline AV-Materialien (Ton-, Bildträger) & 49.481 \\
\hline CD-ROMS & 29.921 \\
\hline Flugblätter & 161.022 \\
\hline Fotos & 586.340 \\
\hline Plakate & 40.253 \\
\hline Feldpostbriefe & 156.114 \\
\hline Porträts & 36.927 \\
\hline $\begin{array}{l}\text { Sonstiges davon: Varia 3.481, Disketten 3.391, Ortsansichten 8.597, Ansichtskarten 37.480, Ereignisdarstellungen 2.000, } \\
\text { Slg. Nicolai 22.00, Einblattmat./Sonstige 3.062, Nachlasse } 161\end{array}$ & 80.172 \\
\hline Bibeln (in 793 Sprachen) & 21.612 \\
\hline Lfd. geh. Zeitschriften u. Zeitungen (Abos) & 8.673 \\
\hline Angebot an elektronischen Zeitschriften & 28.930 \\
\hline Angebot an online-Datenbanken & 331 \\
\hline Angebot an E-Books & 83.537 \\
\hline Zugang 2020 & 59.338 \\
\hline Kauf & 28.795 \\
\hline Pflicht & 24.999 \\
\hline Tausch & 129 \\
\hline Geschenk & 5.415 \\
\hline \multicolumn{2}{|l|}{ Benutzung 2020} \\
\hline Öffnungstage & 229 \\
\hline Öffnungsstunden pro Woche & 64 \\
\hline Entleihungen insgesamt & 988.144 \\
\hline Aktive Benutzer/innen & 42.644 \\
\hline Benutzerfälle in den Lesesälen & 57.196 \\
\hline Benutzerschulungen / Führungen (Stunden) & 69 \\
\hline Fernleihbestellungen (aktiv, pos. erledigt) & 25.666 \\
\hline Fernleihbestellungen (passiv, pos. erledigt) & 12.872 \\
\hline Personalstellen 2020 & 129 \\
\hline Kulturelle Veranstaltungen 2020 & 16 \\
\hline Ausstellungen & 4 \\
\hline Weitere Veranstaltungen & 12 \\
\hline
\end{tabular}

